\title{
Local anaesthetic wound infiltration in addition to standard anaesthetic regimen in total hip and knee replacement: long- term cost-effectiveness analyses alongside the APEX randomised controlled trials
}

\author{
Elsa MR Marques ${ }^{1 *}$, Ashley W. Blom², Erik Lenguerrand ${ }^{2}$, Vikki Wylde ${ }^{2}$ and Sian M. Noble ${ }^{1}$
}

\begin{abstract}
Background: The Arthroplasty Pain Experience (APEX) studies are two randomised controlled trials in primary total hip (THR) and total knee replacement (TKR) at a large UK orthopaedics centre. APEX investigated the effect of local anaesthetic wound infiltration (LAl), administered before wound closure, in addition to standard analgesia, on pain severity at 12 months. This article reports results of the within-trial economic evaluations.

Methods: Cost-effectiveness was assessed from the health and social care payer perspective in relation to quality adjusted life years (QALYS) and the primary clinical outcome, the WOMAC Pain score at 12-months follow-up. Resource use was collected from hospital records and patient-completed postal questionnaires, and valued using unit cost estimates from local NHS Trust finance department and national tariffs. Missing data were addressed using multiple imputation chained equations. Costs and outcomes were compared per trial arm and plotted in cost-effectiveness planes. If no arm was dominant (i.e., more effective and less expensive than the other), incremental cost-effectiveness ratios were estimated. The economic results were bootstrapped incremental net monetary benefit statistics (INMB) and cost-effectiveness acceptability curves. One-way deterministic sensitivity analyses explored any methodological uncertainty.
\end{abstract}

Results: In both the THR and TKR trials, LAI was the dominant treatment: cost-saving and more effective than standard care, in relation to QALYs and WOMAC Pain. Using the $£ 20,000$ per QALY threshold, in THR, the INMB was $£ 1,125$ ( $95 \% \mathrm{BCl}, £ 183$ to $£ 2,067$ ) and the probability of being cost-effective was over $98 \%$. In TKR, the INMB was $£ 264$ ( $95 \% \mathrm{BCl},-£ 710$ to $£ 1,238$ ), but there was only $62 \%$ probability of being cost-effective. When considering an NHS perspective only, LAI was no longer dominant in THR, but still highly cost-effective, with an INMB of $£ 961$ (95\% $\mathrm{BCl}, £ 50$ to $£ 1,873)$.

Conclusions: Administering LAl is a cost-effective treatment option in THR and TKR surgeries. The evidence, because of larger QALY gain, is stronger for THR. In TKR, there is more uncertainty around the economic result, and smaller QALY gains. Results, however, point to LAl being cheaper than standard analgesia, which includes a femoral nerve block.

Trial registration: ISRCTN96095682, 29/04/2010.

Keywords: Cost-effectiveness, Cost-utility, Local anaesthetic wound infiltration, Total hip replacement, Total knee replacement, Trial-based economic evaluation

\footnotetext{
* Correspondence: e.marques@bristol.ac.uk

${ }^{1}$ School of Social and Community Medicine, University of Bristol, Canynge Hall, 39 Whatley Road, Bristol BS8 2PS, UK

Full list of author information is available at the end of the article
} 


\section{Background}

Total hip (THR) and knee replacements (TKR) are common elective procedures with over 150,000 performed annually in the UK NHS [1]. In the USA in 2010, the estimated numbers of hospital discharges after THR and TKR procedures were 332,000 and 719,000 , respectively [2]. For most patients with advanced osteoarthritis, THR and TKR are effective in treating pain and restoring physical function. However, some patients report chronic joint pain after surgery. Evidence suggests that around $20 \%$ of patients with TKR and $10 \%$ of patients with THR report an unfavourable pain outcome at between 3 months and 5 years post-operative [3].

Local anaesthetic wound infiltration (LAI), administered intra-operatively before wound closure, can provide better short-term pain relief and decrease hospital length of stay, but long term effectiveness and costeffectiveness evidence is lacking [4]. In a recent systematic review of LAI, most studies reported outcomes up to 3 months post-surgery, and none of the studies included an economic evaluation of the intervention [4]. The Arthroplasty Pain Experience (APEX) studies are two randomised controlled trials, conducted at a large UK orthopaedic centre, which investigated the effect of intra-operative LAI, in addition to the standard analgesia, on pain severity at 12 months following primary THR and TKR for osteoarthritis [5].

The aim of this article is to report the results of the two within-trial economic evaluations. We assess the cost-effectiveness of LAI, in addition to the usual analgesia regimen, over the 12 months following surgery, from a health and social care payer perspective. In secondary analyses, we explore the economic results using only a health care payer perspective. In sensitivity analyses, we explore uncertainty around costing assumptions. This article follows the CHEERS reporting guidelines (Additional file 1: Appendix 1) [6].

\section{Methods}

The APEX trials were approved by Southampton and South West Hampshire Research Ethics Committee (09/ H0504/94) and all participants provided written informed consent. The trials were registered as an International Standardised Randomized Controlled Trial (96095682) and as a Clinical Trial of an Investigational Medicinal Product with the Medicine Healthcare and Regulatory Authority (18524/0215/001-0001) and EudraCT (2009-013817-93).

The economic evaluations took a health and social care payer perspective: the NHS and Personal Social Services (PSS), in line with the National Institute for Health and Care Excellence (NICE) recommendations [7]. The APEX trials were two double-blinded singlecentre trials in patients undergoing primary THR or
TKR for osteoarthritis [8]. Patients were randomised to receive intra-operative LAI, administered before wound closure, in addition to the standard anaesthetic regimen, or standard anaesthesia alone. Standard anaesthetic care consisted of a spinal anaesthetic alone or in combination with sedation/light general anaesthetic for patients undergoing THR surgery. In TKR, standard care also included administering a femoral nerve block in addition to spinal or general anaesthesia. The primary clinical outcome was the Western Ontario and McMaster Universities Osteoarthritis Index (WOMAC) Pain Scale at 12 months post-operative [9].

The primary economic analyses alongside the APEX trials were cost-utility analyses, whereby incremental costs were compared with incremental quality adjusted life years (QALYs) gained, at 12 months after surgery. The secondary economic analyses compared the incremental costs with increment health benefits measured by the WOMAC Pain score at 12 months follow-up. In addition, we presented results in relation to both health outcomes from an NHS perspective only.

\section{Health outcomes}

The primary health outcome for the APEX trials economic evaluation was the QALY. A QALY is a measure of disease burden that weights survival by quality of life. This generic measure allows for direct effectiveness and cost-effectiveness comparisons between interventions across all patient groups and health conditions. NICE guidelines provide recommendations for UK's societal willingness to pay for one QALY gained [10], which allows for inferences about cost-effectiveness of interventions to be made. QALYs for the APEX trials were derived using the EuroQoL questionnaire (EQ-5D-3L) [11] completed by patients at baseline, and at 3, 6, and 12 months follow-up. The EQ-5D-3L questionnaire comprises five dimensions: mobility, self-care, usual activities, pain/discomfort, and anxiety/depression. Each dimension has three levels: no problems, some problems, or severe problems.

The primary clinical outcome was the WOMAC Pain score, completed by patients at 12 months after surgery. WOMAC Pain scores ranged from 0-100, with lower scores indicating more severe pain.

\section{Resource use identification and collection}

Collection of resource use data was identical for both the THR and TKR trials and related to services used for reasons related to the patients' joint replacement. Resources used at the treating hospital were extracted from medical records onto study-specific proformas. These included the initial inpatient stay for joint replacement, and subsequent inpatient stays and outpatient visits during the 12 months of follow-up. Initial inpatient resource 
use included operating theatre time, intra-operative LAI injection in the intervention group, time spent in recovery, and number of days admitted to a ward after surgery. After initial hospital discharge, inpatient and outpatient resource use data collected included the duration, reason for visit and ward details of inpatient, day-case admissions, accident and emergency visits, and outpatient visits at clinics.

All other resource use was collected using patientcompleted questionnaires, administered by post at 3, 6, and 12 months follow-up. This included secondary care at other hospitals, community-based health care visits, medications use, and use of social services. Community health care included contacts with a doctor, practice nurse, district nurse, community physiotherapist, and occupational therapist contacts. Social services included food at home and home care worker services, contacts with social workers, equipment provided to patients, and changes made to patients' homes during the follow-up period. We excluded services, equipment, and home changes paid for privately by patients.

Patients were provided with resource use logs at hospital discharge, and at 3 and 6 months to facilitate their completion of these questionnaires [12]. Both the logs and the questionnaires were tailored to the type of joint replacement (THR or TKR). Examples of the 3-months resource use questionnaire and log are available online on the DIRUM (Data Instruments for Resource Use Measurement) database [13, 14].

\section{Valuation of resource use}

Resources used during the initial hospital stay were valued using unit costs obtained from the North Bristol Trust finance department. Cost estimates for time spent in theatre, recovery, and admissions to hospital wards included staff time, overheads, consumables, and medications. Unit costs for the LAI injection were provided by the Management and Procurement Department at North Bristol NHS Trust.

For secondary care visits in the 12 months follow-up period, we used information on the reason for inpatient admissions, duration of episode and clinical expert advice to derive healthcare resource group codes. Healthcare resource groups and outpatient appointments by clinical specialty, were valued using Department of Health Reference costs [15].

Community-based resources and personal social services were valued using Curtis' unit costs for health and social care [16]. Equipment and changes to patients' homes, such as dressing aids, furniture raisers, walking aids, and chair lifts, were financed by social services, but provided to patients, on loan, through occupational therapists and physiotherapists at North Bristol Trust. We assumed the useful life of the equipment to be 2 years and valued it as the fraction of equipment cost proportional to the duration of patient use. Unit costs were obtained from equipment suppliers to North Bristol Trust or online sources from other suppliers when procurement costs were not available. Prescribed medications were valued using the British National Formulary 68 [17]. Table 1 describes sources of unit cost estimates.

\section{Data analysis}

The two separate economic evaluations, for THR and TKR, were intention-to-treat analyses and used the same methodology. QALYs were derived for each treatment group, attributing the quality weights from a sample of the UK population to the patients answers to the EQ5D-3L questionnaire [18], at baseline (pre-operative), and at 3, 6, and 12 months follow-up. QALYs were then estimated using the "area under the curve approach", which assumes a linear change between time points [19]. Mean and standard deviations for QALYs were calculated for each group.

Costs were estimated by multiplying units of resource use by their unit cost, reported in 2012-2013 prices (Table 1). Resources were categorised into 17 categories. The total cost for each patient for each of these categories was calculated as the sum of the cost of the resource use items. For each category using all available data, we calculated means and standard deviations for resource use and costs by treatment group. The cost categories were then grouped into initial inpatient stay costs, secondary care costs during the follow-up period, community-based health care costs including medication, and personal social service (PSS) costs. The total individual patient cost for these four groups, as well as total NHS costs and total NHS and PSS costs, were calculated as above. Costs and outcomes were not discounted because of the 1 year duration of follow-up.

Incremental costs for the four main cost groupings, and QALY and WOMAC differences between groups, were then estimated using ordinary least squares regression, adjusting for APEX trial treatment group allocation and randomisation minimisation variables: baseline WOMAC Pain score and surgical approach. QALYs were further adjusted for baseline utility imbalances [19].

Missing cost and outcome data were imputed using chained equations for multiple imputation [20], and Royston's 'ice' command in Stata v13 [21], to generate 20 complete datasets. This method uses regression techniques to estimate missing values, based on the values of available data. Complete datasets for the primary clinical outcome were taken from the statistical analysis of the trial outcomes [5]. The 17 cost categories and four EQ5D utility scores (baseline and three follow-up time points) were imputed jointly, by treatment group allocation, adjusting for the primary clinical outcome, trial 
Table 1 Unit costs for total hip and knee replacement resource use

\begin{tabular}{|c|c|c|c|}
\hline Resource use & Unit cost & Assumption & Source \\
\hline \multicolumn{4}{|l|}{ Initial inpatient admission } \\
\hline Theatre (per minute) & $£ 14.22$ & $\begin{array}{l}\text { Includes implant cost, staff time, overheads, } \\
\text { consumables, facilities }\end{array}$ & $\begin{array}{l}\text { North Bristol NHS Trust Finance } \\
\text { department }\end{array}$ \\
\hline Injection of local anaesthesia infiltration (LAI) & $£ 2.00$ & $\begin{array}{l}\text { Box of bupivicaine with adrenaline } 0.25 \% / 1 \text { in } \\
200,000 \text { is } £ 20.00 \text {; one box contains } 10 \text { ampoules }\end{array}$ & $\begin{array}{l}\text { North Bristol NHS Trust Finance } \\
\text { department, management, and } \\
\text { procurement }\end{array}$ \\
\hline Recovery (per minute) & $£ 3.84$ & $\begin{array}{l}\text { Includes staff time with overheads, consumables, } \\
\text { facilities, and medications administered during } \\
\text { stay; base cost per minute }\end{array}$ & $\begin{array}{l}\text { North Bristol NHS Trust Finance } \\
\text { department }\end{array}$ \\
\hline $\begin{array}{l}\text { Day in general orthopaedics ward: Frome, Severn, } \\
\text { Kennett, and Cardiac Care Unit }\end{array}$ & $£ 311$ & $\begin{array}{l}\text { Includes staff time with overheads, consumables, } \\
\text { facilities, and medications administered during } \\
\text { stay; base cost per day }\end{array}$ & $\begin{array}{l}\text { North Bristol NHS Trust Finance } \\
\text { department }\end{array}$ \\
\hline Day in other orthopaedics ward: Chew & $£ 250$ & $\begin{array}{l}\text { Includes staff time with overheads, consumables, } \\
\text { facilities, and medications administered during } \\
\text { stay; base cost per day }\end{array}$ & $\begin{array}{l}\text { North Bristol NHS Trust Finance } \\
\text { department }\end{array}$ \\
\hline Day in high dependency unit & $£ 1,356$ & $\begin{array}{l}\text { Includes staff time with overheads, consumables, } \\
\text { facilities, and medications administered during } \\
\text { stay; base cost per day }\end{array}$ & $\begin{array}{l}\text { North Bristol NHS Trust Finance } \\
\text { department }\end{array}$ \\
\hline
\end{tabular}

Inpatient admissions following discharge from initial surgery

Revision surgery - Total knee replacement (TKR) $\quad £ 9,439$

Revision surgery - Total hip replacement (THR)

Manipulation under anaesthetic - TKR

Infections

Day case procedures - TKR

$£ 655$

Day case procedures - THR

$£ 788$

Nights in hospital for other admissions ${ }^{a}$

$A$ and $E$ and outpatient visits

Accident and emergency

Trauma and orthopaedics - consultant led

Trauma and orthopaedics - non-consultant led

Physiotherapy - non-consultant led

General Medicine - consultant led

Neurology - consultant led

Respiratory - consultant led
HB22A major knee procedures for non-trauma, with major comorbidity and complication (CC)

HB12A major hip procedures for non-trauma, with major CC

HB24C minor knee procedures for non-trauma, category 2, without CC

Infections of bones or joints, with CC Score 5-8

Day case: HB29Z minimal knee procedures for non-trauma

Day case: HB19Z minimal hip procedures for non-trauma

Unit cost based on SMH cost per night in general orthopaedics ward

Average of all accident and emergency visits

Non-admitted face to face attendance, follow-up, consultant led

Non-admitted face to face attendance, follow-up, non-consultant led

Non-admitted face to face attendance, follow-up, non-consultant led

Non-admitted face to face attendance, follow-up, consultant led

Non-admitted face to face attendance, follow-up, consultant led

Non-admitted face to face attendance, first appointment, consultant led
NHS Reference Costs 2012-2013: Non-elective long stay

NHS Reference Costs 2012-2013: Non-elective long stay

NHS Reference Costs 2012-2013: Non-elective long stay

NHS Reference Costs 2012-2013: Non-elective long stay

NHS Reference Costs 2012-2013: Non-elective day case

NHS Reference Costs 2012-2013: Non-elective day case

North Bristol NHS Trust Finance department

NHS Reference Costs 2012-2013: Outpatient appointments: 180 Accident \& Emergency

NHS Reference Costs 2012-2013: Outpatient appointments: 110 Trauma \& Orthopaedics

NHS Reference Costs 2012-2013: Outpatient appointments: 110 Trauma \& Orthopaedics

NHS Reference Costs 2012-2013: Outpatient appointments: 650 Physiotherapy

NHS Reference Costs 2012-2013: Outpatient appointments: 300 General Medicine

NHS Reference Costs 2012-2013: Outpatient appointments: 400 Neurology

NHS Reference Costs 2012-2013: Outpatient appointments: 340 Respiratory Medicine 
Table 1 Unit costs for total hip and knee replacement resource use (Continued)

\begin{tabular}{|c|c|c|}
\hline Pain management - consultant led & $£ 136$ & $\begin{array}{l}\text { Non-admitted face to face attendance, } \\
\text { follow-up, consultant led }\end{array}$ \\
\hline Vascular - consultant led & $£ 133$ & $\begin{array}{l}\text { Non-admitted face to face attendance, } \\
\text { follow-up, consultant led }\end{array}$ \\
\hline Dermatology - consultant led & $£ 95$ & $\begin{array}{l}\text { Non-admitted face to face attendance, } \\
\text { follow-up, consultant led }\end{array}$ \\
\hline Haematology - consultant led & $£ 209$ & $\begin{array}{l}\text { Non-admitted face to face attendance, } \\
\text { follow-up, consultant led }\end{array}$ \\
\hline
\end{tabular}

Community based health services

GP surgery visit

GP home visit

Phoned GP for advice

GP Practice nurse visit

Phoned GP practice nurse for advice

Repeat prescription (without seeing doctor)

District nurse

Occupational therapist at home/ GP surgery/clinic

Community physiotherapist at home/

GP surgery/clinic

Prescriptions costs per consultation

Social services

Home care worker (home help) provided by social services

Food at home service (meals on wheels)

Social worker visits
Base cost per patient contact with GP with qualifications, including direct care staff costs, lasting $11.7 \mathrm{~min}$

Base cost per out of surgery visit with GP with qualifications, including direct care

$£ 27 \quad$ Base cost per telephone consultation with GP with qualifications, including direct care staff costs, lasting $7.1 \mathrm{~min}$

$£ 13.43$ Based on 15.5 min per surgery consultation using the base cost (£52) of one hour of face-to-face contact with GP nurse with qualifications

$£ 4$ Based on 6 min of GP nurse time using the base cost (£40) of 1 hour of GP nurse time with qualifications

$£ 11.40$ Based on 3 min of GP time, using the base cost of 1 minute GP patient contact time (£3.80), with qualifications, including direct care staff costs

$£ 18.08$ Based on the assumption that the duration of a district nurse visit is the same as GP nurse visit (15.5 min) and using the base cost of 1 hour of community nurse visit (£70) with qualifications including travel

$£ 17 \quad$ Based on 30 min contact using the base cost (£34) of 1 hour of occupational therapist contact with qualifications

$£ 17$ Based on 30 min contact using the base cost (£34) of 1 hour of physiotherapist contact with qualifications

$£ 44.64$ Prescription costs per consultation (net ingredient cost)

$£ 24$ Based on 1 hour of face-to-face weekday contact for independent sector home care provided for social services

Based on one meal a day using the Meals on Wheels average weekly cost (2012/2013) of $£ 44$, assuming two meals per day, 7 days a week

$£ 113$ Based on a 30 min visit using the base cost (£226) of 1 hour of face-to-face contact of social worker with qualifications staff costs, lasting 23.4 min
NHS Reference Costs 2012-2013:

Outpatient appointments: 191

Pain management

NHS Reference Costs 2012-2013:

Outpatient appointments: 107

Vascular surgery

NHS Reference Costs 2012-2013:

Outpatient appointments: 330

Dermatology

NHS Reference Costs 2012-2013:

Outpatient appointments: 303

Clinical Haematology

Personal Social Services Research Unit (PSSRU) 2013: 10.8b General practitioner

PSSRU 2013: 10.8b General practitioner

PSSRU 2013: 10.8b General practitioner

PSSRU 2013: 10.6 Nurse (GP practice)

PSSRU 2013: 10.6 Nurse (GP practice)

PSSRU 2013: 10.8b General practitioner

PSSRU 2013: 10.1 Community nurse

PSSRU 2013: 9.2 NHS community occupational therapist

PSSRU 2013: 9.1 Community physiotherapist

PSSRU 2013:10.8b General practitioner

PSSRU 2013: 11.6

PSSRU 2013: 8.1.1 Community care package for older people: very low cost

PSSRU 2013: 11.2 Social worker (adult services) 
Table 1 Unit costs for total hip and knee replacement resource use (Continued)

\begin{tabular}{|c|c|c|c|}
\hline Social worker telephone calls & $£ 39.50$ & $\begin{array}{l}\text { Based on a } 30 \text { min telephone call using a } \\
\text { base cost ( } £ 79 \text { ) of } 1 \text { hour of client-related } \\
\text { work of a social worker with qualifications }\end{array}$ & $\begin{array}{l}\text { PSSRU 2013: } 11.2 \text { Social worker } \\
\text { (adult services) }\end{array}$ \\
\hline $\begin{array}{l}\text { Home changes and equipment provided by } \\
\text { social services: }\end{array}$ & & $\begin{array}{l}\text { All unit costs for home changes and } \\
\text { equipment are based on 3-month loan } \\
\text { period, assuming a } 24 \text { months life span }\end{array}$ & \\
\hline Toilet seat or toilet raiser & $£ 1.80$ & Cost of equipment $£ 14$ & $\begin{array}{l}\text { NRS price - equipment provider } \\
\text { for North Bristol NHS Trust }\end{array}$ \\
\hline Dressing aids: socks, shoes, etc. & $£ 1.25$ & Cost of equipment $£ 10$ & $\begin{array}{l}\text { NRS price - equipment provider } \\
\text { for North Bristol NHS Trust }\end{array}$ \\
\hline Furniture raisers & $£ 2.48$ & Cost of equipment $£ 20$ & $\begin{array}{l}\text { NRS price - equipment provider } \\
\text { for North Bristol NHS Trust }\end{array}$ \\
\hline Perching stool & $£ 6.00$ & Cost of equipment $£ 48$ & $\begin{array}{l}\text { NRS price - equipment provider } \\
\text { for North Bristol NHS Trust }\end{array}$ \\
\hline Walker or trolley & $£ 7.50$ & Cost of equipment $£ 60$ & $\begin{array}{l}\text { NRS price - equipment provider } \\
\text { for North Bristol NHS Trust }\end{array}$ \\
\hline Crutches & $£ 3.75$ & Cost of equipment $£ 30$ & $\begin{array}{l}\text { NRS price - equipment provider } \\
\text { for North Bristol NHS Trust }\end{array}$ \\
\hline Commode & $£ 5.69$ & Cost of equipment $£ 46$ & $\begin{array}{l}\text { NRS price - equipment provider } \\
\text { for North Bristol NHS Trust }\end{array}$ \\
\hline Rails and hand grips & $£ 2.85$ & Cost of equipment $£ 23$ & $\begin{array}{l}\text { NRS price - equipment provider } \\
\text { for North Bristol NHS Trust }\end{array}$ \\
\hline Bath boards & $£ 3.00$ & Cost of equipment $£ 24$ & $\begin{array}{l}\text { NRS price - equipment provider } \\
\text { for North Bristol NHS Trust }\end{array}$ \\
\hline Hospital bed at home & $£ 59.88$ & Cost of equipment $£ 479$ & $\begin{array}{l}\text { Online search for procurement } \\
\text { prices (cheaper range) }\end{array}$ \\
\hline Bath lift & $£ 44.75$ & Cost of equipment $£ 358$ & $\begin{array}{l}\text { Online search for procurement } \\
\text { prices (cheaper range) }\end{array}$ \\
\hline Chair and stair lift & $£ 125.00$ & Cost of equipment $£ 1000$ & $\begin{array}{l}\text { Online search for procurement } \\
\text { prices (cheaper range) }\end{array}$ \\
\hline
\end{tabular}

${ }^{a}$ When healthcare resource group codes could not be derived because of insufficient information, inpatient admissions were valued multiplying the number of nights admitted to a ward by the cost of a night in a general orthopaedics ward provided by the North Bristol Trust finance department

minimisation variables, and patient baseline characteristics: age, sex, body mass index, and dichotomous variables for education level (high vs medium or low) and marital status (single vs married or other). QALYs and grouped cost categories were then recalculated using the imputed values, and incremental costs and both outcomes with imputed data were then re-estimated adjusting for the same variables as described in the regression models above.

The incremental costs and outcomes (QALYs and WOMAC Pain scores) were presented in a cost-consequences table and depicted on cost-effectiveness planes. If no treatment was dominant, an incremental cost-effectiveness ratio (ICER) was estimated [22]. The ICER is a ratio that divides the difference in mean costs between arms by the difference in mean outcomes.

The incremental net monetary benefits (INMB) of the intervention were estimated in relation to QALYs, given that this health outcome has recommended UK societal willingness-to-pay thresholds [10]. The INMB statistic is estimated by multiplying the incremental health gain observed in the intervention, compared with control, by the societal willingness-to-pay thresholds for that health gain $(\lambda)$, and then deducting the incremental cost difference [23]. We used thresholds of $£ 10,000$ per QALY, a threshold closer to recent valuations of QALYs for the UK [24], and the NICE recommendations of $£ 20,000$ and $£ 30,000$ per QALY [7]. Positive INMB statistics indicate a cost-effective intervention, whereby society is willing to pay more for the health gain than what the intervention costs. To account for the uncertainty around the economic results, bootstrapped confidence intervals (BCI) with 1,000 replications were estimated for the adjusted costs, outcomes, the INMB statistics, and ICERs. Bootstrapped costs and effects were depicted in cost-effectiveness planes [25]. In cost-effectiveness acceptability curves (CEACs), we illustrated the probability of the intervention being cost-effective, given a range of societal willingness-to-pay thresholds. All analyses were conducted using Stata v13 [26]. In secondary analysis, we presented the results from a narrower perspective: the NHS perspective only. 


\section{Sensitivity analyses}

In one-way deterministic sensitivity analyses, we explored methodological and sample uncertainty around the economic results in relation to QALYs and the WOMAC Pain score. In the first scenario, we assumed a macro-costing approach to the prescribed medications, using the national average value of prescriptions costs per general practitioner (GP) consultation [16], and multiplying it by the number of the GP consultations attended by the patient. Secondly, we explored the potential variation in the local trust cost estimates for the initial inpatient stay: theatre and recovery costs, LAI injection, and daily admission rates to wards, using worst and best case scenarios where local costs could be up to $50 \%$ higher, or $50 \%$ lower, than our local trust. In the THR trial, we explored the variation in the results from excluding two high cost patients: one patient in the control group, who was an intensive user of home care help, and one patient in the intervention group, who required further surgeries with high hospital re-admission costs.
All sensitivity analyses were performed from NHS and PSS perspectives. Imputation models for all cost categories and utility scores were redone accounting for changes in sensitivity analysis.

\section{Results and discussion The APEX trials}

The APEX trials recruited 322 patients undergoing THR and 316 patients undergoing TKR between November 2009 and February 2012. In the THR trial, patients in the intervention group had less pain at 12 months post-operatively, and were more likely to report none to moderate pain than severe pain compared to the standard care group. In the TKR trial, there was no strong evidence that LAI influenced pain severity at 12 months post-operative. The clinical outcomes of the APEX trials are reported in full elsewhere [5].

In the THR trial, 88/163 (54\%) patients in the intervention group and 85/159 (53\%) patients in the standard care group had complete NHS and PSS cost data (Table 2). In the TKR trial, the corresponding figures

Table 2 Mean resource use and cost by APEX trial treatment group for total hip replacements (available cases)

\begin{tabular}{|c|c|c|c|c|c|c|c|c|c|c|}
\hline & \multicolumn{5}{|c|}{ Intervention } & \multicolumn{5}{|c|}{ Control } \\
\hline & $\mathrm{N}$ & Mean resource use & $(\mathrm{SD})$ & Mean cost & (SD) & $\mathrm{N}$ & Mean resource use & $(\mathrm{SD})$ & Mean cost & (SD) \\
\hline \multicolumn{11}{|l|}{ Initial inpatient stay } \\
\hline Theatre time (in minutes) & 148 & 99 & 29 & $£ 1,407$ & $£ 411$ & 147 & 101 & 31.6 & $£ 1,441$ & $£ 449$ \\
\hline Recovery time (in minutes) & 143 & 103 & 65 & $£ 397$ & $£ 251$ & 144 & 113 & 77.4 & $£ 435$ & $£ 297$ \\
\hline Days in wards & 153 & 5.2 & 3.3 & $£ 1,597$ & $£ 1,516$ & 154 & 5.2 & 2.8 & $£ 1,553$ & $£ 886$ \\
\hline \multicolumn{11}{|l|}{ Secondary care after initial discharge } \\
\hline Inpatient admissions after initial discharge ${ }^{a}$ & 115 & & & $£ 341$ & $£ 1,847$ & 122 & & & $£ 101$ & $£ 554$ \\
\hline Orthopaedics appointments & 142 & 1.96 & 1.2 & $£ 199$ & $£ 121$ & 146 & 1.97 & 1.4 & $£ 201$ & $£ 138$ \\
\hline Physiotherapy appointments & 142 & 0.19 & 0.8 & $£ 7$ & $£ 32$ & 146 & 0.23 & 0.8 & $£ 9$ & $£ 30$ \\
\hline Accident and emergency visits & 142 & 0.06 & 0.4 & $£ 7$ & $£ 46$ & 146 & 0.04 & 0.3 & $£ 5$ & $£ 30$ \\
\hline Other appointments & 142 & 0.04 & 0.3 & $£ 5$ & $£ 37$ & 146 & 0.04 & 0.3 & $£ 7$ & $£ 59$ \\
\hline \multicolumn{11}{|l|}{ Community-based resources } \\
\hline GP contacts combined & 107 & 1.90 & 3.3 & $£ 61$ & $£ 113$ & 108 & 2.66 & 4.5 & $£ 83$ & $£ 145$ \\
\hline Nurse contacts combined & 110 & 1.60 & 4.1 & $£ 25$ & $£ 70$ & 114 & 1.24 & 2.7 & $£ 18$ & $£ 41$ \\
\hline Occupational therapist contacts combined & 113 & 0.04 & 0.4 & $£ 1$ & $£ 7$ & 116 & 0.08 & 0.5 & $£ 1$ & $£ 8$ \\
\hline $\begin{array}{l}\text { Community physiotherapist contacts } \\
\text { combined }\end{array}$ & 109 & 0.25 & 1.1 & $£ 4$ & $£ 19$ & 113 & 0.58 & 1.8 & $£ 10$ & $£ 30$ \\
\hline Prescribed medications ${ }^{a}$ & 113 & & & $£ 22$ & $£ 77$ & 120 & & & $£ 21$ & $£ 55$ \\
\hline Total NHS cost ${ }^{b}$ & 92 & & & $£ 3,773$ & $£ 1,557$ & 87 & & & $£ 3,762$ & $£ 1,065$ \\
\hline \multicolumn{11}{|l|}{ Personal social services (PSS) } \\
\hline Home care worker (in hours) & 139 & 1.11 & 8.1 & $£ 27$ & $£ 195$ & 144 & 5.36 & 56.3 & $£ 129$ & $£ 1,351$ \\
\hline Meals (food at home services) & 137 & 2.76 & 24.0 & $£ 9$ & $£ 75$ & 138 & 0.00 & 0.0 & $£ 0$ & $£ 0$ \\
\hline Contacts with social worker & 138 & 0.05 & 0.5 & $£ 4$ & $£ 36$ & 144 & 0.13 & 1.1 & $£ 7$ & $£ 59$ \\
\hline Home changes $^{a}$ & 161 & & & $£ 1$ & $£ 3$ & 158 & & & $£ 2$ & $£ 5$ \\
\hline Total NHS+PSS cost ${ }^{b}$ & 88 & & & $£ 3,837$ & $£ 1,642$ & 85 & & & $£ 3,948$ & $£ 2,108$ \\
\hline
\end{tabular}

${ }^{a}$ The category combines different types of resource use, therefore an overall mean resource use could not be calculated

b Total costs computed for patients with complete cost categories 
were $70 / 157$ (45 \%) for the intervention group, and 75/ $159(47 \%)$ for the control group (Table 3). Complete cost and QALY data were available for 159 patients in the THR trial (49\%) and 142 patients in the TKR trial (45 \%; not reported). Given the amount of missing data, our primary economic results statistics included imputed missing cost and outcome data.

\section{Resource use and costs}

Tables 2 and 3 show the observed mean and standard deviations for the resource use and costs by treatment group, and by resource use category, for all participants with data. All available data is reported for each category.

For both the THR and TKR trials, the available case results indicate that initial inpatient stay cost categories are similar between groups. Administering intra-operative LAI does not appear to increase operation time, but may reduce time in recovery by about $10 \mathrm{~min}$. The length of stay following recovery was, on average, 5.2 days for both arms of the THR trial, and 5.9 days for the intervention group of the TKR trial compared to 5.2 days in the standard care group.

After initial discharge, there were lower readmission costs for TKR patients in the intervention group, whereas the reverse was true for patients receiving THR. Participants in both arms of the two trials had a similar number of appointments in the period.

In both trials, the intervention group seemed to have less contacts with a doctor compared with the control group, but more nurse contacts in the THR trial. Personal social services costs contributed a minor amount to the overall costs of delivering treatment for both types of joint replacement. Total unadjusted mean NHS and PSS cost was lower in the intervention group than the control group for both trials. All cost drivers for these trials display high variability, with large standard deviations around the categorical mean cost estimates.

Table 3 Mean resource use and cost by APEX trial treatment group for total knee replacements (available cases)

\begin{tabular}{|c|c|c|c|c|c|c|c|c|c|c|}
\hline & \multicolumn{5}{|c|}{ Intervention } & \multicolumn{5}{|c|}{ Control } \\
\hline & $\mathrm{N}$ & Mean resource use & $(\mathrm{SD})$ & Mean cost & (SD) & $\mathrm{N}$ & Mean resource use & $(\mathrm{SD})$ & Mean cost & $(S D)$ \\
\hline \multicolumn{11}{|l|}{ Initial inpatient stay } \\
\hline Theatre time (in minutes) & 142 & 102 & 32 & $£ 1,449$ & $£ 453$ & 145 & 103 & 32.9 & $£ 1,461$ & $£ 469$ \\
\hline Recovery time (in minutes) & 140 & 94 & 44 & $£ 359$ & $£ 169$ & 136 & 104 & 69.1 & $£ 398$ & $£ 265$ \\
\hline Days in wards & 147 & 5.9 & 3.9 & $£ 1,789$ & $£ 1,224$ & 149 & 5.2 & 2.9 & $£ 1,586$ & $£ 1,034$ \\
\hline \multicolumn{11}{|l|}{ Secondary care after initial discharge } \\
\hline Inpatient admissions after initial discharge ${ }^{a}$ & 103 & & & $£ 104$ & $£ 533$ & 110 & & & $£ 296$ & $£ 907$ \\
\hline Orthopaedics appointments & 128 & 2.06 & 1.5 & $£ 209$ & $£ 149$ & 137 & 1.99 & 1.4 & $£ 202$ & $£ 143$ \\
\hline Physiotherapy appointments & 128 & 0.44 & 2.1 & $£ 17$ & $£ 82$ & 137 & 0.40 & 1.3 & $£ 16$ & $£ 50$ \\
\hline Accident and emergency visits & 128 & 0.16 & 0.7 & $£ 18$ & $£ 84$ & 137 & 0.18 & 1.2 & $£ 20$ & $£ 145$ \\
\hline Other appointments & 128 & 0.00 & 0.0 & $£ 0$ & $£ 0$ & 137 & 0.03 & 0.2 & $£ 4$ & $£ 34$ \\
\hline \multicolumn{11}{|l|}{ Community Based resources } \\
\hline GP contacts combined & 85 & 2.65 & 4.3 & $£ 84$ & $£ 151$ & 102 & 3.83 & 5.7 & $£ 122$ & $£ 212$ \\
\hline Nurse contacts combined & 90 & 0.98 & 1.4 & $£ 14$ & $£ 22$ & 104 & 1.09 & 2.7 & $£ 16$ & $£ 43$ \\
\hline Occupational therapist contacts combined & 95 & 0.28 & 1.1 & $£ 5$ & $£ 19$ & 105 & 0.25 & 1.3 & $£ 4$ & $£ 22$ \\
\hline $\begin{array}{l}\text { Community physiotherapist contacts } \\
\text { combined }\end{array}$ & 90 & 1.03 & 2.7 & $£ 18$ & $£ 45$ & 107 & 1.29 & 3.5 & $£ 22$ & $£ 60$ \\
\hline Prescribed medications ${ }^{a}$ & 102 & & & $£ 61$ & $£ 211$ & 108 & & & $£ 48$ & $£ 81$ \\
\hline Total NHS cost ${ }^{b}$ & 70 & & & $£ 3,807$ & $£ 1,277$ & 78 & & & $£ 4,255$ & $£ 1,804$ \\
\hline \multicolumn{11}{|l|}{ Personal social services (PSS) } \\
\hline Home care worker (in hours) & 135 & 1.17 & 12.9 & $£ 28$ & $£ 310$ & 136 & 1.24 & 14.4 & $£ 30$ & $£ 346$ \\
\hline Meals (food at home services) & 132 & 0.14 & 1.6 & $£ 0$ & $£ 5$ & 129 & 0.11 & 1.2 & $£ 0$ & $£ 4$ \\
\hline Contacts with social worker & 133 & 0.11 & 1.1 & $£ 4$ & $£ 45$ & 134 & 0.14 & 1.6 & $£ 7$ & $£ 84$ \\
\hline Home changes $^{a}$ & 157 & & & $£ 3$ & $£ 13$ & 158 & & & $£ 1$ & $£ 4$ \\
\hline Total NHS+PSS cost ${ }^{b}$ & 70 & & & $£ 3,811$ & $£ 1,276$ & 75 & & & $£ 4,303$ & $£ 2,102$ \\
\hline
\end{tabular}

${ }^{a}$ The category combines different types of resource use, therefore an overall mean resource use could not be calculated

${ }^{\mathrm{b}}$ Total costs computed for patients with complete cost categories 


\section{Adjusted outcomes and costs}

Tables 4 (THR) and 5 (TKR) report the costs and outcome differences between arms. In THR, patients in the intervention arm had an incremental QALY gain of 0.052 (95\% BCI, 0.01 to 0.09 ) compared with the control group. This corresponded to patients in the intervention arm spending on average an estimated 19 more days in "perfect health" than patients in the control arm. In TKR, the estimated health benefit gain for the intervention arm was lower and findings were more uncertain, with a mean of 0.009 QALYs gained per patient in the intervention arm $(95 \% \mathrm{BCI},-0.04$ to 0.057$)$. In relation to the primary clinical result, patients in the intervention arm receiving THR experienced a greater reduction in pain severity at 12 months, by 5.35 points on the WOMAC Pain scale (95\% CI, 1.33 to 9.34) compared to the control arm. In TKR, there was weaker evidence for the pain reduction observed, with patients in the intervention arm experiencing less pain at 12 months by 3.33 points on the WOMAC Pain scale $(95 \%$ CI, -1.21 to 7.88$)$.

In both THR and TKR, differences in the imputed and adjusted NHS, and NHS and PSS costs, indicated that patients in the intervention group had lower mean costs

Table 4 Total hip replacement: differences in costs and outcomes between APEX randomised groups

\begin{tabular}{|c|c|c|c|}
\hline & \multicolumn{3}{|c|}{ Difference (intervention - control) } \\
\hline & $\mathrm{N}$ & Mean & $(95 \% \mathrm{Cl})$ \\
\hline \multicolumn{4}{|l|}{ OUTCOMES } \\
\hline \multicolumn{4}{|l|}{ QALYS } \\
\hline QALY gain - available cases ${ }^{a}$ & 216 & 0.064 & (0.018 to 0.110$)$ \\
\hline QALY gain - imputed data ${ }^{b}$ & 322 & 0.052 & (0.011 to 0.094$)$ \\
\hline \multicolumn{4}{|l|}{ Primary clinical outcome } \\
\hline WOMAC pain score improvement - available cases ${ }^{c}$ & 281 & 4.74 & (0.95 to 8.54$)$ \\
\hline WOMAC pain score improvement - imputed data ${ }^{d}$ & 322 & 5.35 & (1.33 to 9.34$)$ \\
\hline \multicolumn{4}{|l|}{ COST } \\
\hline \multicolumn{4}{|l|}{ Initial inpatient stay } \\
\hline Total of inpatient stay - available cases ${ }^{a}$ & 273 & $-£ 123$ & $(£-364$ to $£ 118)$ \\
\hline Total of inpatient stay - imputed data ${ }^{b}$ & 322 & $-£ 32$ & ( $£-349$ to $£ 285)$ \\
\hline \multicolumn{4}{|l|}{ Secondary care after initial discharge } \\
\hline Inpatient admissions - available cases ${ }^{a}$ & 236 & $£ 251$ & $(£-114$ to $£ 617)$ \\
\hline Inpatient admissions - imputed data ${ }^{b}$ & 322 & $£ 139$ & $(£-174$ to $£ 452)$ \\
\hline Outpatient visits - available cases ${ }^{a}$ & 287 & $-£ 2$ & $(£-36$ to $£ 32)$ \\
\hline Outpatient visits with - imputed data ${ }^{\mathrm{b}}$ & 322 & $£ 4$ & $(£-33$ to $£ 42)$ \\
\hline Total secondary care cost - available cases ${ }^{a}$ & 231 & $£ 251$ & $(£-136$ to $£ 639)$ \\
\hline Total secondary care cost - imputed data ${ }^{\mathrm{b}}$ & 322 & $£ 143$ & $(£-184$ to $£ 471)$ \\
\hline \multicolumn{4}{|l|}{ Community-based resources } \\
\hline Total community-based costs - available cases ${ }^{\text {a }}$ & 202 & $-€ 4$ & $(£-51$ to $£ 43)$ \\
\hline Total community-based costs - imputed data ${ }^{\mathrm{b}}$ & 322 & $-£ 34$ & $(£-83$ to $£ 16)$ \\
\hline Total NHS cost - complete NHS cost cases ${ }^{a}$ & 179 & $£ 15$ & $(£-373$ to $£ 404)$ \\
\hline Total NHS cost - imputed data ${ }^{b}$ & 322 & $£ 78$ & $(£-404$ to $£ 560)$ \\
\hline \multicolumn{4}{|l|}{ Personal social services (PSS) } \\
\hline Total personal social services - available cases ${ }^{\text {a }}$ & 263 & $-£ 83$ & ( $£-289$ to $£ 123)$ \\
\hline Total personal social services - imputed data ${ }^{\text {b }}$ & 322 & $-£ 164$ & $(£-418$ to $£ 91)$ \\
\hline Total NHS + PSS cost - complete NHS+PSS cost cases ${ }^{a}$ & 173 & $-£ 94$ & $(£-634$ to $£ 446)$ \\
\hline Total NHS + PSS cost - imputed data ${ }^{\mathrm{b}}$ & 322 & $-£ 86$ & $(£-634$ to $£ 462)$ \\
\hline
\end{tabular}

${ }^{a}$ Adjusted for minimisation variables (baseline WOMAC pain score and surgical approach) and baseline utility for QALYs, robust standard errors

${ }^{b}$ Adjusted for minimisation variables (and baseline utility for QALYs), robust standard errors, $\mathrm{M}=20$ multiple imputation sets, bootstrapped confidence intervals with 1000 replications

${ }^{c}$ Adjusted for minimisation variables (baseline WOMAC pain score and surgical approach) and baseline utility for QALYs

${ }^{\mathrm{d}}$ Adjusted for minimisation variables, $\mathrm{M}=20$ multiple imputation sets from main statistical analysis 
Table 5 Total knee replacement: differences in costs and outcomes between APEX randomised groups

\begin{tabular}{|c|c|c|c|}
\hline & \multicolumn{3}{|c|}{ Difference (intervention - control) } \\
\hline & $\mathrm{N}$ & Mean & $(95 \% \mathrm{Cl})$ \\
\hline \multicolumn{4}{|l|}{ OUTCOMES } \\
\hline \multicolumn{4}{|l|}{ QALYS } \\
\hline QALY gain - available cases ${ }^{a}$ & 201 & 0.010 & $(-0.039$ to 0.060$)$ \\
\hline QALY gain - imputed data ${ }^{b}$ & 316 & 0.009 & $(-0.040$ to 0.057$)$ \\
\hline \multicolumn{4}{|l|}{ Primary clinical outcome } \\
\hline WOMAC pain score improvement - available cases ${ }^{c}$ & 273 & 3.83 & $(-0.83$ to 8.49$)$ \\
\hline WOMAC pain score improvement - imputed data ${ }^{d}$ & 316 & 3.33 & $(-1.21$ to 7.88$)$ \\
\hline \multicolumn{4}{|l|}{ COST } \\
\hline \multicolumn{4}{|l|}{ Initial inpatient stay } \\
\hline Total of inpatient stay - available cases ${ }^{a}$ & 268 & $£ 89$ & $(£-194$ to $£ 371)$ \\
\hline Total of inpatient stay - imputed data ${ }^{b}$ & 316 & $£ 152$ & $(£-140$ to $£ 444)$ \\
\hline \multicolumn{4}{|l|}{ Secondary care after initial discharge } \\
\hline Inpatient admissions - available cases ${ }^{a}$ & 213 & $-£ 170$ & $(£-365$ to $£ 24)$ \\
\hline Inpatient admissions - imputed data ${ }^{\mathrm{b}}$ & 316 & $-£ 239$ & $(£-489$ to $£ 11)$ \\
\hline Outpatient visits - available cases ${ }^{a}$ & 265 & $£ 2$ & $(£-47$ to $£ 52)$ \\
\hline Outpatient visits with - imputed data ${ }^{b}$ & 316 & $£ 13$ & $(£-43$ to $£ 70)$ \\
\hline Total secondary care cost - available cases ${ }^{a}$ & 203 & $-£ 165$ & $(£-391$ to $£ 61)$ \\
\hline Total secondary care cost - imputed data ${ }^{\mathrm{b}}$ & 316 & $-£ 226$ & $(£-485$ to $£ 34)$ \\
\hline \multicolumn{4}{|l|}{ Community-based resources } \\
\hline Total community based costs - available cases ${ }^{\text {a }}$ & 170 & $-£ 56$ & $(£-142$ to $£ 31)$ \\
\hline Total community based costs - imputed data ${ }^{b}$ & 316 & $£ 0$ & (£-99 to $£ 99)$ \\
\hline Total NHS cost - complete NHS cost cases ${ }^{a}$ & 148 & $-£ 343$ & $(£-822$ to $£ 137)$ \\
\hline Total NHS cost - imputed data ${ }^{\mathrm{b}}$ & 316 & $-£ 74$ & (£-490 to $£ 343)$ \\
\hline \multicolumn{4}{|l|}{ Personal social services (PSS) } \\
\hline Total personal social services - available cases ${ }^{\text {a }}$ & 259 & $-£ 4$ & $(£-95$ to $£ 87)$ \\
\hline Total personal social services - imputed data ${ }^{b}$ & 316 & $-£ 4$ & $(£-89$ to $£ 82)$ \\
\hline Total NHS + PSS cost - complete NHS+PSS cost cases ${ }^{a}$ & 145 & $-£ 404$ & $(£-924$ to $£ 117)$ \\
\hline Total NHS + PSS cost - imputed data ${ }^{\mathrm{b}}$ & 316 & $-£ 77$ & $(£-528$ to $£ 374)$ \\
\hline
\end{tabular}

${ }^{a}$ Adjusted for minimisation variables (baseline WOMAC c pain score and surgical approach) and baseline utility for QALYs, robust standard errors

${ }^{b}$ Adjusted for minimisation variables (and baseline utility for QALYs), robust standard errors, $M=20$ multiple imputation sets, bootstrapped confidence intervals with 1000 replications

c Adjusted for minimisation variables (baseline WOMAC pain score and surgical approach) and baseline utility for QALYs

${ }^{\mathrm{d}}$ Adjusted for minimisation variables, $\mathrm{M}=20$ multiple imputation sets from main statistical analysis

than those in the standard care group at 1 year. In THR, the mean cost per patient in the intervention group was $£ 32$ lower for the initial inpatient stay $(95 \% \mathrm{BCI}, £-349$ to $£ 285$ ), $£ 34$ lower for community-based health care costs ( $95 \% \mathrm{BCI}, £-83$ to $£ 16$ ), and $£ 139$ more for readmission costs ( $95 \% \mathrm{BCI}, £-174$ to $£ 452$ ), when compared with the control group, with mean overall NHS costs higher by $£ 78$ ( $95 \% \mathrm{BCI}, £-404$ to $£ 560$ ). Mean PSS costs were lower in the intervention arm by $£ 164$ per patient (95\% BCI, $£-418$ to $£ 91$ ). Therefore, the combined NHS and PSS mean cost per patient was $£ 86$ lower in the intervention group ( $95 \% \mathrm{BCI}, £-634$ to $£ 462$ ).
In contrast, in TKR, the mean cost per patient for the initial inpatient stay in the intervention arm was greater by $£ 152$ ( $95 \% \mathrm{BCI}, £-140$ to $£ 444$ ) and the mean cost per patient of hospital readmissions was lower by $£ 239$ (95\% BCI, $£-489$ to $£ 11$ ). Therefore, there was an overall lower combined NHS and PSS mean cost of $£ 77$ (95\% BCI, $£-528$ to $£ 374$ ) per patient in the intervention group compared with the control group.

\section{Economic results: NHS and PSS perspective}

The cost and outcome results indicate that LAI, in addition to standard analgesia, is the dominant treatment 
option in the two trials: cost-saving and more effective, both in relation to QALYs and pain severity at 12 months, than current clinical practice. Tables 6 and 7 present the cost-effectiveness results in THR and TKR, respectively. Given that the intervention was dominant, no incremental cost-effectiveness ratios were calculated for the base case results.

In THR, the INMB statistics are positive, even at the more stringent willingness-to-pay per QALY thresholds. The mean INMB for the NICE-recommended $£ 20,000$ per QALY threshold was of $£ 1,125$ (95 \% BCI, $£ 183$ to
$£ 2,067)$. In TKR, our findings also indicate positive INMB statistics at all willingness-to-pay thresholds, but more uncertainty around these estimates, with all bootstrapped confidence intervals crossing the null.

Figure 1 plots the 1,000 replications of the adjusted bootstrapped incremental cost-effectiveness estimates in the cost-effectiveness planes and the corresponding CEACs for the various willingness-to-pay per QALY thresholds. Most estimates fall within the southeast quadrant of the plane, indicating the dominance of the intervention over standard care, more notably so for

Table 6 Total hip replacement economic results

\begin{tabular}{|c|c|c|c|c|}
\hline & \multicolumn{4}{|c|}{${ }_{\text {Difference (intervention - control) }}{ }^{a}$} \\
\hline & $\mathrm{N}$ & Mean & $(95 \% \mathrm{Cl})$ & $P$ value \\
\hline \multicolumn{5}{|c|}{ MAIN ANALYSIS: NHS and personal social services (PSS) perspective } \\
\hline Mean QALY gain & 322 & 0.052 & (0.017 to 0.087$)$ & 0.004 \\
\hline Mean NHS+PSS cost difference & 322 & $-£ 86$ & ( $£-571$ to $£ 399)$ & 0.730 \\
\hline Incremental net monetary benefit - lambda $£ 10,000$ & 322 & $£ 606$ & $(£-55$ to $£ 1,266)$ & 0.072 \\
\hline Incremental net monetary benefit - lambda $£ 20,000$ & 322 & $£ 1,125$ & ( $£ 183$ to $£ 2,067)$ & 0.019 \\
\hline Incremental net monetary benefit - lambda £30,000 & 322 & $£ 1,645$ & ( $£ 385$ to $£ 2,905)$ & 0.011 \\
\hline \multicolumn{5}{|l|}{ SECONDARY ANALYSIS: NHS perspective only } \\
\hline Mean NHS cost difference & 322 & $£ 78$ & $(£-347$ to $£ 502)$ & 0.720 \\
\hline Incremental net monetary benefit - lambda $£ 20,000$ & 322 & $£ 961$ & ( $£ 50$ to $£ 1,873)$ & 0.039 \\
\hline Incremental Cost per point in WOMAC pain decrease ${ }^{b}$ & 322 & $£ 16$ & $(£-16,591 \text { to } £ 16,622)^{c}$ & 0.999 \\
\hline \multicolumn{5}{|c|}{ SENSITIVITY ANALYSIS: Using macro-costed prescribed medications } \\
\hline Prescribed medications ${ }^{b}$ & 322 & $-£ 24$ & $(£-28$ to $£-20)$ & \\
\hline Mean QALY gain & 322 & 0.052 & (0.017 to 0.087$)$ & 0.004 \\
\hline Mean NHS+PSS cost difference & 322 & $-£ 107$ & ( $£-590$ to $£ 376)$ & 0.660 \\
\hline Incremental Net Monetary Benefit - lambda $£ 20,000$ & 322 & $£ 1,666$ & ( $£ 406$ to $£ 2,925)$ & 0.010 \\
\hline \multicolumn{5}{|l|}{ SENSITIVITY ANALYSIS: 50 \% higher local inpatient costs } \\
\hline Initial inpatient stay ${ }^{b}$ & 322 & $-£ 50$ & $(£-156$ to $£ 56)$ & \\
\hline Mean QALY gain & 322 & 0.052 & (0.017 to 0.088$)$ & 0.004 \\
\hline Mean NHS+PSS cost difference & 322 & $-£ 106$ & ( $£-697$ to $£ 485)$ & 0.730 \\
\hline Incremental net monetary benefit - lambda £20,000 & 322 & $£ 1,151$ & $(£ 121$ to $£ 2,181)$ & 0.028 \\
\hline \multicolumn{5}{|l|}{ SENSITIVITY ANALYSIS: $50 \%$ lower local inpatient costs } \\
\hline Initial inpatient stay ${ }^{b}$ & 322 & $-£ 8$ & $(£-44$ to $£ 27)$ & \\
\hline Mean QALY gain & 322 & 0.050 & (0.015 to 0.086$)$ & 0.006 \\
\hline Mean NHS+PSS cost difference & 322 & $-£ 44$ & ( $£-445$ to $£ 358)$ & 0.830 \\
\hline Incremental net monetary benefit - lambda $£ 20,000$ & 322 & $£ 1,051$ & (£164 to $£ 1,938)$ & 0.020 \\
\hline \multicolumn{5}{|l|}{ SENSITIVITY ANALYSIS: dropping high cost patients } \\
\hline Mean QALY gain & 320 & 0.052 & (0.016 to 0.088$)$ & 0.004 \\
\hline Mean NHS+PSS cost difference & 320 & $-£ 73$ & $(£-449$ to $£ 302)$ & 0.70 \\
\hline Incremental net monetary benefit - lambda $£ 20,000$ & 320 & $£ 1,121$ & ( $£ 215$ to $£ 2,026)$ & 0.015 \\
\hline
\end{tabular}


Table 7 Total knee replacement economic results

\begin{tabular}{|c|c|c|c|c|}
\hline & \multicolumn{4}{|c|}{ Difference (intervention - control) ${ }^{a}$} \\
\hline & $\mathrm{N}$ & Mean & $(95 \% \mathrm{Cl})$ & $P$ value \\
\hline \multicolumn{5}{|c|}{ MAIN ANALYSIS: NHS and personal social services (PSS) perspective } \\
\hline Mean QALY gain & 316 & 0.009 & $(-0.030$ to 0.049$)$ & 0.64 \\
\hline Mean NHS+PSS Cost difference & 316 & $-£ 77$ & $(£-451$ to $£ 296)$ & 0.68 \\
\hline Incremental net monetary benefit - lambda $£ 10,000$ & 316 & $£ 171$ & $(£-452$ to $£ 793)$ & 0.59 \\
\hline Incremental net monetary benefit - lambda $£ 20,000$ & 316 & $£ 264$ & $(£-710$ to $£ 1,238)$ & 0.60 \\
\hline Incremental net monetary benefit - lambda $£ 30,000$ & 316 & $£ 357$ & $(£-992$ to $£ 1,707)$ & 0.60 \\
\hline \multicolumn{5}{|l|}{ SECONDARY ANALYSIS: NHS perspective only } \\
\hline Mean QALY gain & 316 & 0.009 & $(-0.030$ to 0.049$)$ & 0.64 \\
\hline Mean NHS cost difference & 316 & $-£ 74$ & $(£-414$ to $£ 266)$ & 0.67 \\
\hline Incremental net monetary benefit - lambda $£ 20,000$ & 316 & 260 & $(£-690$ to $£ 1,210)$ & 0.59 \\
\hline \multicolumn{5}{|c|}{ SENSITIVITY ANALYSIS: using macro-costed prescribed medications } \\
\hline Prescribed medications ${ }^{b}$ & 316 & $-£ 14$ & $(£-21$ to $£-6)$ & \\
\hline Mean QALY gain & 316 & 0.009 & $(-0.030$ to 0.049$)$ & 0.64 \\
\hline Mean NHS+PSS cost difference & 316 & $-£ 121$ & $(£-491$ to $£ 249)$ & 0.52 \\
\hline Incremental net monetary benefit - lambda $£ 20,000$ & 316 & $£ 308$ & $(£-665$ to $£ 1,281)$ & 0.53 \\
\hline \multicolumn{5}{|l|}{ SENSITIVITY ANALYSIS: $50 \%$ higher local inpatient costs } \\
\hline Initial inpatient stay ${ }^{\text {b }}$ & 316 & $-£ 258$ & (£164 to $£ 353)$ & \\
\hline Mean QALY gain & 316 & 0.008 & $(-0.032$ to 0.047$)$ & 0.70 \\
\hline Mean NHS+PSS cost difference & 316 & $-£ 2$ & ( $£-483$ to $£ 478)$ & 0.99 \\
\hline Incremental net monetary benefit - lambda $£ 20,000$ & 316 & $£ 159$ & $(£-882$ to $£ 1,200)$ & 0.76 \\
\hline \multicolumn{5}{|l|}{ SENSITIVITY ANALYSIS: $50 \%$ lower local inpatient costs } \\
\hline Initial inpatient stay ${ }^{\text {b }}$ & 316 & $£ 84$ & $(£-66$ to $£ 234)$ & \\
\hline Mean QALY gain & 316 & 0.006 & $(-0.034$ to 0.045$)$ & 0.79 \\
\hline Mean NHS+PSS cost difference & 316 & $-£ 143$ & ( $£-423$ to $£ 137)$ & 0.32 \\
\hline Incremental net monetary benefit - lambda $£ 20,000$ & 316 & $£ 253$ & $(£-674$ to $£ 1,180)$ & 0.59 \\
\hline
\end{tabular}

THR than TKR. The CEAC shows the uncertainty around the economic results, with a probability of LAI being cost-effective in TKR only slightly over $60 \%$ at the $£ 20,000$ threshold. In THR, there is over $98 \%$ probability of LAI being cost-effective at $£ 20,000$ per QALY and over $95 \%$ at $£ 10,000$ per QALY.

\section{Economic results: NHS perspective}

From an NHS perspective, LAI in addition to usual analgesia is no longer a dominant strategy in THR, albeit highly cost-effective, with an INMB of $£ 961$ (95\% BCI, $£ 50$ to $£ 1,873$; Table 6 ). There is considerably more uncertainty around the cost-effectiveness estimate in relation to decrease in pain severity measured by the WOMAC Pain scale at $£ 16$ per decrease in one point of pain (95\% CI, $£-16,591$ to $£ 16,622$ ). In TKR, LAI is still the cheapest and most effective intervention, in relation to both QALYs, with an INMB statistic of $£ 260$ ( $\lambda=20,000 ; 95 \%$ BCI, $-£ 690$ to $£ 1,210$, Table 7 ), and WOMAC pain, from an NHS perspective only.

\section{Sensitivity analysis results}

Our results in THR (Table 6) are robust to costing method of medication use, with an INMB statistic at the $£ 20,000$ per QALY threshold only slightly higher than base case. Varying local trust cost estimates during the initial patient stay by a factor of $50 \%$ higher or lower did not alter our results, whereby the intervention is still dominant in both surgeries. In THR, the INMB statistics range from $£ 1,051$, using lower local costs, to $£ 1,151$, when higher local costs were used, compared with $£ 1,125$ in the base case. In TKR (Table 7), the respective 


\section{Total Hip Replacement}
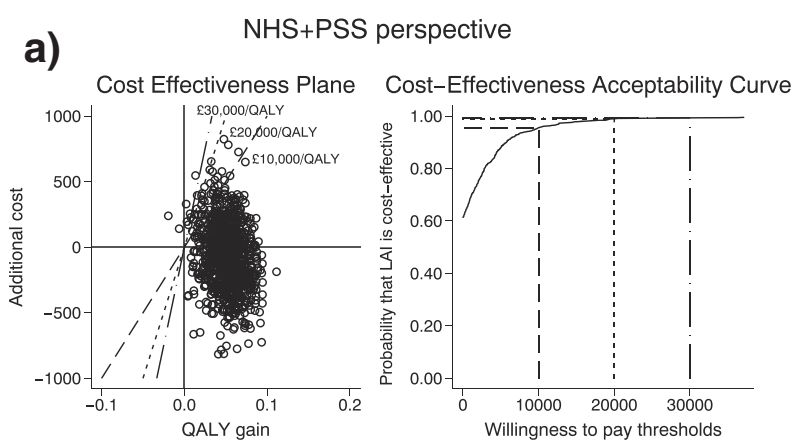

NHS perspective
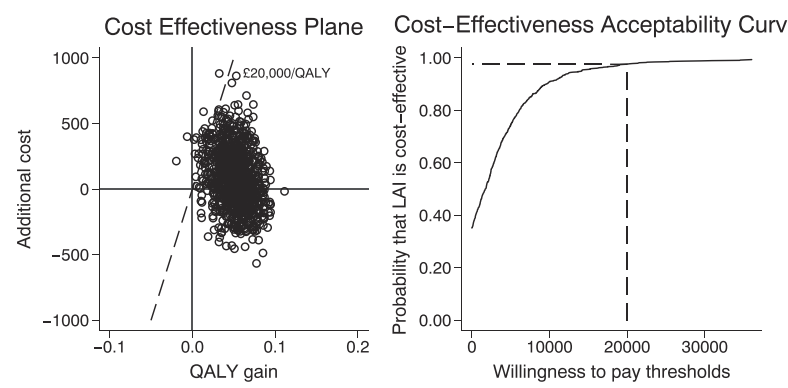

Total Knee Replacement

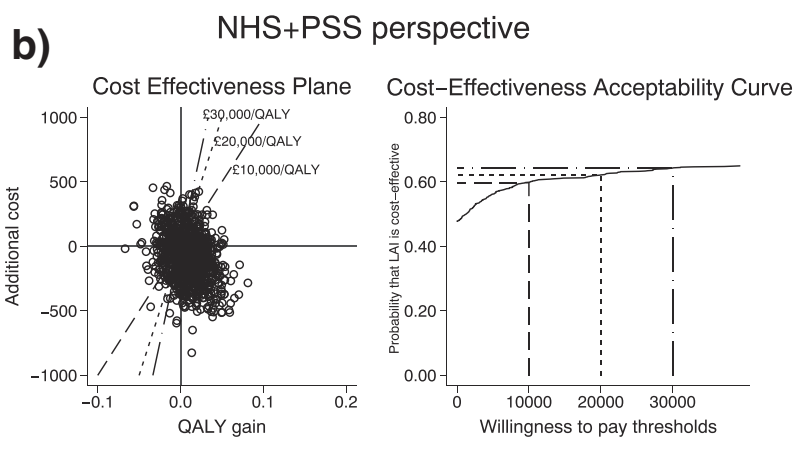

NHS perspective
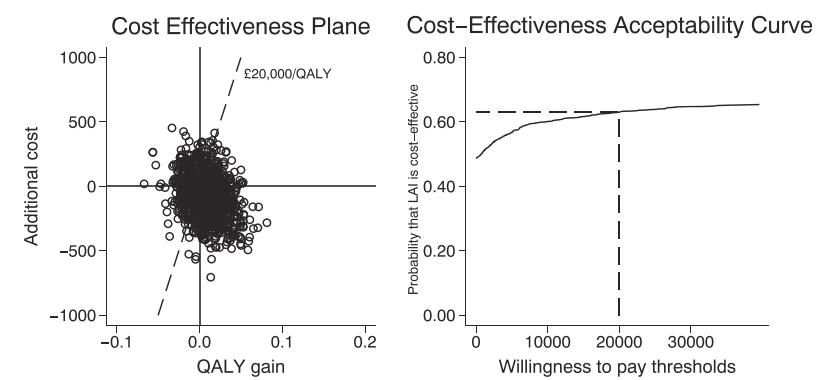

Fig. 1 a. Total hip replacement: primary and secondary analyses cost-effectiveness plane and cost-acceptability curve. b. Total knee replacement: base care cost-effectiveness plane and cost-acceptability curve

figures are $£ 253$ and $£ 159$, compared with $£ 264$ in the base case. Due to changes in the components of the imputation model, QALY estimates vary slightly, particularly in TKR for these scenarios. In the scenario where we drop two high cost patients in THR, LAI is also the dominant treatment option with an INMB statistic of $£ 1,121$ ( $\lambda=20,000 ; 95 \% C I, £ 215$ to $£ 2,026)$. Figure 2a portrays the cost-effectiveness planes and CEACs for the scenarios, displaying probabilities of LAI being the costeffective treatment option of over $98 \%$ at the $£ 20,000$ per QALY threshold in THR. For TKR (Fig. 2b), sensitivity analysis results are consistent with base case results with just over $60 \%$ probability of LAI being costeffective at the $£ 20,000$ threshold.

\section{Discussion}

Our findings suggest that administering LAI before wound closure is a cost-effective treatment option compared to current clinical analgesia regimens in both primary THR and TKR surgeries. The evidence is stronger for THR than TKR, with large positive INMB and a probability of LAI being cost-effective of over $95 \%$ across all scenarios. There is no strong evidence for the positive INMB statistics for TKR, although results point to LAI being the dominant treatment option with a $62 \%$ probability of being cost-effective at current NICE thresholds of $£ 20,000$ per QALY. There was little difference in costs between the two arms in both trials, with the cost-effectiveness results being driven by the QALY gain, which is larger in the THR trial. This higher QALY gain in the THR also accounts for the difference in economic results between trials. From an NHS perspective, in relation to THR, the intervention is no longer dominant, but still highly cost effective.

Our study is the first, to our knowledge, to report a trial based economic evaluation of LAI in the longer-term for patients receiving THR and TKR. The economic results of our trials reinforce the effectiveness results, and together provide evidence that the intervention is both effective and cost-effective in THR. There is more uncertainty around the effectiveness and cost-effectiveness results for TKR, where patients already benefit from a femoral nerve block in standard care. Given that there are no safety concerns with the treatment $[27,28]$, it should be recommended for use in patients having a THR.

Our study is not without limitations. The economic evaluation was carried out alongside the APEX trials, which were powered to detect a difference in the primary clinical outcome between treatment groups, but not in the cost-effectiveness outcomes. Collection of resource use data, particularly community-based health 


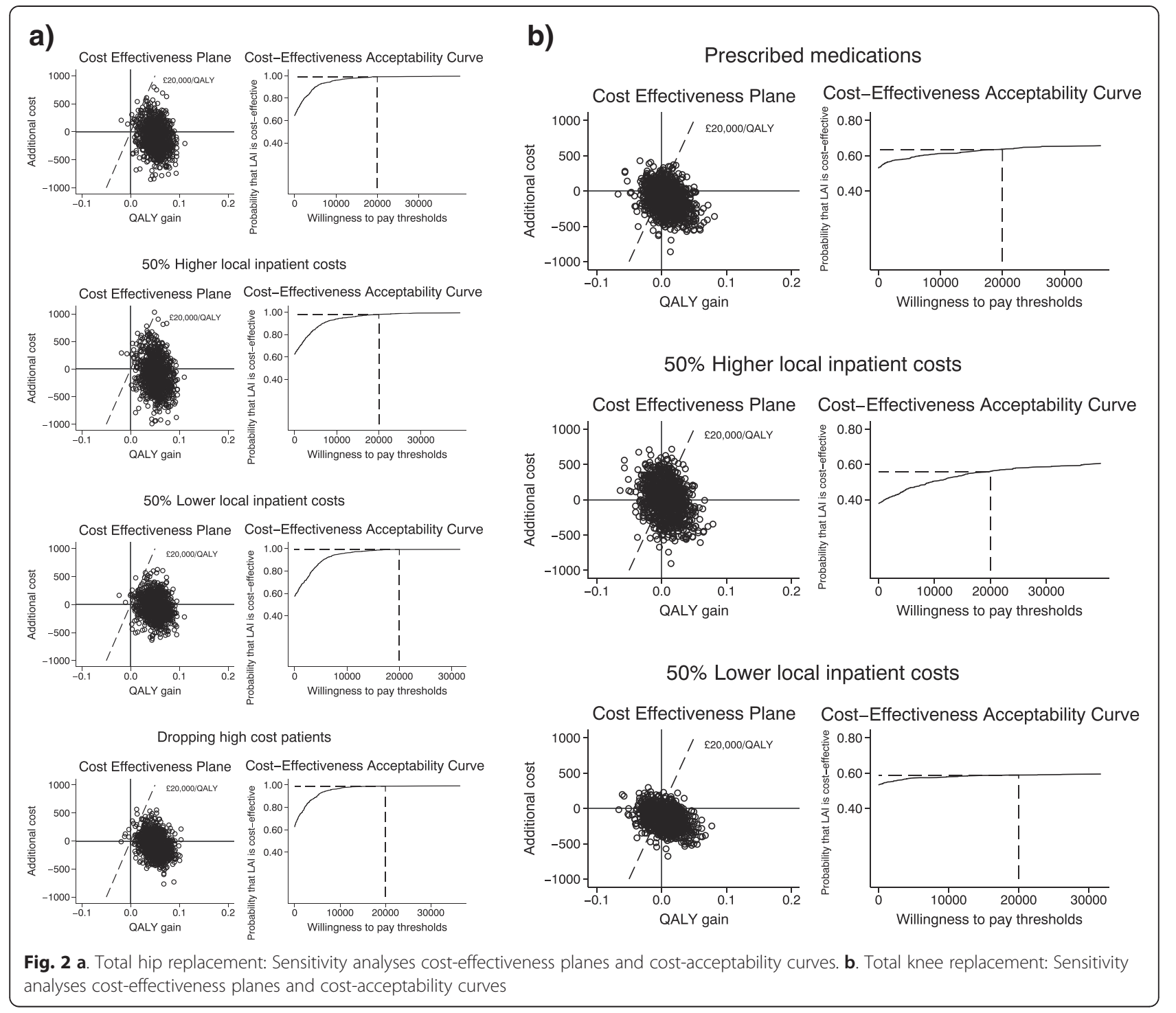

and social services, relied on patient-reported data, completed by postal questionnaires at three follow-up points. This led to a substantial amount of missing data and imputation was therefore needed. The imputed value estimates varied substantially from available case estimates. Patients with complete cost and QALY data had better pain outcomes. This was, however, accounted for in our imputation model, which included WOMAC Pain outcomes as a predictor of costs and QALYs, for a more conservative economic result. It would, therefore, be unlikely that the interventions would not to be cost-effective at current NICE recommended thresholds, even if complete cost and QALY data had been obtained. Local estimates for the initial hospital were used rather than national tariffs to allow for the disaggregation of this stay. This could potentially limit the generalisability of the results to other hospital locations. However, there were only minor differences in resource use in the micro-costed items. A sensitivity analysis which altered these local unit costs showed the initial results to be robust.

\section{Conclusions}

Our findings suggest that administering LAI before wound closure is a cost-effective treatment option compared to current clinical analgesia regimens in both primary THR and TKR surgeries. The evidence, because of larger QALY gains, is stronger for THR. In TKR, there is more uncertainty around the economic result, and smaller QALY gains. Results, however, point to LAI being cheaper than standard analgesia, which already includes a femoral nerve block. 


\section{Additional file}

Additional file 1: Appendix 1. CHEERS checklist.

\section{Abbreviations}

APEX: The Arthroplasty pain experience (APEX) trials; CEAC: Cost-effectiveness acceptability curve; EQ-5D-3L: EuroQol questionnaire; ICER: Incremental Cost-effectiveness ratio; INMB: Incremental net monetary benefit; LAI: Local anaesthetic infiltration; PSS: Personal social service; QALY: Quality adjusted life year; THR: Total hip replacement; TKR: Total knee replacement; WOMAC: Western Ontario and McMaster Universities Osteoarthritis Index.

\section{Competing interests}

The authors declare no competing interests. The funder had no role in study design, data collection, data analysis, data interpretation, or writing of this article. This article presents independent research funded by the National Institute for Health Research (NIHR) under its Programme Grants for Applied Research programme (RP-PG-0407-10070).

\section{Authors' contributions}

$A W B, W W$, and SN were involved in the concept and design of the APEX trials. $\mathrm{SN}$ designed the economic evaluation. EM performed the economic evaluation and drafted the article. SN revised the article for content. EL managed the APEX databases and provided raw data for analysis and multiple imputation estimates of primary clinical outcome. All authors critically reviewed the article and approved the final version of the manuscript.

\section{Acknowledgements}

This article reports trial-based economic evaluations alongside the two APEX trials. Collaborators to the APEX trial, who were instrumental to the work that allowed this evaluation to take place included: Dr Rachael Gooberman-Hill, Mr Andrew Beswick, Professor Paul Dieppe, and Dr Mark Pyke. We would like to acknowledge the RESTORE team and the APEX trial team, and all the research nurses in particular, for collecting economic data. We would like to thank Louise Hawkins and Diana Pratt for aiding data cleaning and completing missing records. We would like to thank Adrian Sayers for his contribution to the management of the APEX databases. At the North Bristol NHS Trust, we would like to thank Mike Iwasiuk at the Finance Department for providing unit cost estimates for total hip and total knee replacement surgery and Cath Hale for information on Occupational therapy equipment procurement. We would like to thank Dr Sandra Hollinghurst for methodological advice and Dr Rachael Gooberman-Hill for helpful comments. Named RESTORE team collaborators: Dr Rachael Gooberman-Hill, Mr Andrew Beswick, Professor Paul Dieppe, and Dr Mark Pyke.

\section{Financial support}

This article presents independent research funded by the National Institute for Health Research (NIHR) under its Programme Grants for Applied Research programme (RP-PG-0407-10070). The views expressed in this article are those of the authors and not necessarily those of the NHS, the NIHR, or the Department of Health. The research team acknowledge the support of the $\mathrm{NIHR}$, through the Comprehensive Clinical Research Network.

\section{Author details}

${ }^{1}$ School of Social and Community Medicine, University of Bristol, Canynge Hall, 39 Whatley Road, Bristol BS8 2PS, UK. ${ }^{2}$ Musculoskeletal Research Unit, School of Clinical Sciences, University of Bristol, Learning and Research Building, Southmead Hospital, Bristol BS10 5NB, UK.

\section{Received: 6 February 2015 Accepted: 3 June 2015}

\section{Published online: 26 June 2015}

\section{References}

1. National Joint Registry for England Wales and the Northern Ireland. 11th Annual Report. Hemel Hempstead: NJR Centre. 2014.

2. Centers for Disease Control and Prevention/NCHS. National Hospital Discharge Survey: 2010 table, Procedures by selected patient characteristics Number by procedure category and age. http://www.cdc.gov/nchs/data/nhds/ 4procedures/2010pro4_numberprocedureage.pdf. 2010.
3. Beswick AD, Wylde V, Gooberman-Hill R, Blom A, Dieppe P. What proportion of patients report long-term pain after total hip or knee replacement for osteoarthritis? A systematic review of prospective studies in unselected patients. BMJ Open. 2012;2, e000435.

4. Marques EMR, Jones HE, Elvers KT, Pyke M, Blom AW, Beswick AD. Local anaesthetic infiltration for peri-operative pain control in total hip and knee replacement: systematic review and meta-analyses of short- and long-term effectiveness. BMC Musculoskelet Disord. 2014;15:220.

5. Wylde V, Lenguerrand E, Gooberman-Hill R, Beswick AD, Marques E, Noble $S$, et al. The effect of local anaesthetic infiltration on chronic post-surgical pain after total hip and knee replacement: The APEX randomised controlled trials. Pain. 2015;156(6):1161-70.

6. Husereau D, Drummond M, Petrou S, Carswell C, Moher D, Greenberg D, et al. Consolidated Health Economic Evaluation Reporting Standards (CHEERS) statement. Value Health. 2013;16:e1-5.

7. National Institute for Health and Clinical Excellence. Guide to the methods of technology appraisal 2013. London: NICE; 2013.

8. Wylde V, Gooberman-Hill R, Horwood J, Beswick A, Noble S, Brookes S, et al. The effect of local anaesthetic wound infiltration on chronic pain after lower limb joint replacement: a protocol for a double-blind randomised controlled trial. BMC Musculoskelet Disord. 2011;12:53.

9. Bellamy N, Buchanan WW, Goldsmith CH, Campbell J, Stitt LW. Validation study of WOMAC: a health status instrument for measuring clinically important patient relevant outcomes to antirheumatic drug therapy in patients with osteoarthritis of the hip or knee. J Rheumatol. 1988;15:1833-40.

10. National Institute for Health and Clinical Excellence. Guide to the methods of technology appraisal 2013: Section 6.3 'Decision-Making'. London: NICE; 2013.

11. The EuroQol Group. EuroQol-a new facility for the measurement of health-related quality of life. Health Policy. 1990;16:199-208.

12. Marques E, Johnson EC, Gooberman-Hill R, Blom AW, Noble S. Using resource use logs to reduce the amount of missing data in economic evaluations alongside trials. Value Health. 2013;16:195-201.

13. Noble S. APEX - Hip replacement participant resource use log: 0 to 3 months. DIRUM; 2012. http://www.dirum.org/instruments/details/54.

14. Noble S. APEX - 3-month post-operative hip questionnaire. DIRUM; 2012 http://www.dirum.org/instruments/details/55.

15. Department of Health. NHS reference costs: financial year 2012 to 2013. https://www.gov.uk/government/publications/nhs-reference-costs-2012-to-2013.

16. Curtis L. Unit costs of health and social care 2013. Personal Social Services Research Unit. Canterbury: University of Kent; 2014

17. Joint Formulary Committee. British National Formulary. 68th ed. London: BMJ Group and Pharmaceutical Press; 2014.

18. Dolan P, Gudex C, Kind P, Williams A. A social tariff for EuroQol: results from a UK general population survey. Working Papers, vol. 138 chedp. York: University of York, Centre for Health Economics; 1995

19. Manca A, Hawkins N, Sculpher MJ. Estimating mean QALYs in trial-based cost-effectiveness analysis: the importance of controlling for baseline utility. Health Econ. 2005;14:487-96.

20. White $I R$, Royston $P$, Wood AM. Multiple imputation using chained equations: Issues and guidance for practice. Stat Med. 2011;30:377-99.

21. Royston P. Multiple imputation of missing values: update. Stata J. 2005;5:188-201.

22. Weinstein MC, Stason WB. Foundations of cost-effectiveness analysis for health and medical practices. N Engl J Med. 1977;296:716-21.

23. Hoch JS, Briggs AH, Willan AR. Something old, something new, something borrowed, something blue: a framework for the marriage of health econometrics and cost-effectiveness analysis. Health Econ. 2002;11:415-30.

24. Claxton K, Martin S, Soares M, Rice N, Spackman E, Hinde S, Devlin N, Smith PC, Sculpher M. Methods for the estimation of the NICE cost effectiveness threshold. Health Technology Assessment 2015;19(14):doi10.3310/hta19140.

25. Black WC. The CE, plane: a graphic representation of cost-effectiveness. Med Decis Making. 1990;10:212-4.

26. StataCorp. Stata Statistical Software: Release 13. College Station, TX: StataCorp LP; 2013.

27. Busch CA, Whitehouse MR, Shore BJ, MacDonald SJ, McCalden RW, Bourne RB. The efficacy of periarticular multimodal drug infiltration in total hip arthroplasty. Clin Orthop Relat Res. 2010;468:2152-9.

28. Koh IJ, Kang YG, Chang CB, Do SH, Seong SC, Kim TK. Does periarticular injection have additional pain relieving effects during contemporary multimodal pain control protocols for TKA? A randomised, controlled study. Knee. 2012:19:253-9. 